\title{
Development of novel multifunction directly compressible co-processed excipient by melt granulation technique
}

\author{
Nidhi Garg, Parijat Pandey, Deepak Kaushik, Harish Dureja \\ Department of Pharmaceutical Sciences, M.D. University, Rohtak, Haryana, India
}

\begin{abstract}
Introduction: The objective of the present investigation was to develop a novel multifunctional directly compressible co-processed excipient consisting of dibasic calcium phosphate anhydrous, polyethylene glycol 4000 (PEG 4000 ) and crospovidone using Box-Behnken design. Materials and Methods: The technique of melt granulation was adopted for the preparation of the co-processed excipient. The percentage of crospovidone $(5-10 \% \mathrm{w} / \mathrm{w})$, percentage of PEG 4000 $(5-15 \% \mathrm{w} / \mathrm{w})$ and the heating time $(4-12 \mathrm{~min})$ were selected as independent variables. The co-processed granules were evaluated for bulk density, tapped density, Hausner's ratio and Carr's index. Placebo tablets of co-processed granules were prepared and evaluated for hardness, friability and disintegration time. Multiple linear regression was applied to develop mathematical models for hardness, Carr' index and disintegrating time. ANOVA was applied to study the fitting and significance of the model. The optimized batches (BB) were selected for further studies. The selected batches were characterized for particle size distribution, granular friability index, moisture uptake study, differential scanning calorimetry, Fourier transform infrared spectroscopy and scanning electron microscopy. Aceclofenac was selected as model drug for the preparation of tablets. Results: Aceclofenac tablets prepared using co-processed excipients showed better hardness, disintegration time and in vitro drug release as compared to aceclofenac tablets prepared using conventional wet granulation method. Conclusion: The developed co-processed excipient can serve as a novel co-processed excipient for improvement of tableting characteristics.
\end{abstract}

Key words: Aceclofenac, Box-Behnken design, co-processed excipient, melt granulation, tablets

\section{INTRODUCTION}

The solid dosage forms in general and tablets in particular, owing to its patient convenience; accurate dosing; stability; large scale production and cost effectiveness, remains one of the most preferred pharmaceutical dosage forms. Tablets are manufactured mainly by wet granulation, dry granulation and direct compression. ${ }^{[1]}$ A recent survey by Shangraw and Demarest reveals that pharmaceutical industries in contemporary times

\section{Address for correspondence:}

Dr. Harish Dureja,

Department of $\mathrm{P}$ harmaceutical Sciences, M.D. University,

Rohtak - 124 001, Haryana, India.

E-mail: harishdureja@gmail.com

\begin{tabular}{|l|l|}
\hline \multicolumn{2}{|c|}{ Access this article online } \\
\hline Quick Response Code: & Website: \\
\hline & www.jpionline.org \\
\cline { 2 - 4 } & DOI: \\
\hline
\end{tabular}

are more inclined toward direct compression process. ${ }^{[2]}$ The reason for its preference lies in its numerous advantages, such as, fewer unit operations, its suitability for moisture and heat sensitive active pharmaceuticals and improved drug dissolution when compared with wet granulation. However, the direct compression process requires excipients with good flowability, compressibility and dilution potential. However, most of the available excipients fail to meet the desired functional characteristics. Therefore, creating an opportunity for the development of high functionality excipients (HFE) is the need of hour. ${ }^{[3]}$

High functionality excipients can be obtained either as new chemical excipients, improved grades of existing excipients, combinations of existing excipients via co-processing. ${ }^{[4]}$ The involvement of high risk and significant investment has demotivated the development of new chemical excipients. Many improved grades of existing excipients such as spray dried mannitol, microcrystalline cellulose, pregel starch has been quiet successful. However, because of the narrow window for modification, the extent of functionality improvement that could be obtained was limited. ${ }^{[5]}$ In the recent years, co-processing has emerged as an attractive tool for the development of 
HFE. Co-processing is another way that new excipients are coming to market without undergoing the rigorous safety testing of a completely new chemical. ${ }^{[6]}$ It can be defined as combining two or more established excipients by an appropriate process. ${ }^{[7]}$ Co-processing of excipients could lead to the formation of excipients with superior properties compared to the simple physical mixtures of their components. The main aim of co-processing is to obtain the product with added value related to the ratio of its functionality/price. Co-processing is interesting because the products are physically modified in a special way without altering the chemical structure. A fixed and homogenous distribution for the components is achieved by embedding them within mini granules. Segregation is diminished by adhesion of the actives on the porous particles making process validation and in process control easy and reliable. ${ }^{[8]}$ Numerous studies have suggested that co-processed excipients showed better characteristics than alone excipients the controlled optimal particle size and particle size distribution ensures superior flow properties of co-processed excipients without the need to add glidents. ${ }^{[9]}$ The pressure-hardness relation of co-processed excipients, when plotted and compared with simple physical mixtures, showed a marked improvement in the compressibility profile. ${ }^{[10]}$ The production of synergism in functionality of individual components; reduction of company's regulatory concern because of absence of chemical change during co-processing; improvement in physico-chemical properties such as dilution potential, flowability, compressibility efforts are few examples. ${ }^{[1]}$ The multifold advantages offered by co-processed excipients such as production of synergism in functionality of individual components, reduction of company's regulatory concern because of absence of chemical change during co-processing and improvement in physico-chemical properties have expanded their use in the pharmaceutical industry. ${ }^{[12]}$ Today, a large number of co-processed excipients are available in pharmaceutical market, for example, ProSolv, Starlac, Advantose FS-95, Avicel CE-15, Ludipress, etc. Most of these excipients have been developed using spray drying technique. ${ }^{[13]}$ The utility of the co-processed excipients can easily be demonstrated by formulating the tablets. In the present study, the aceclofenac was used as a model drug. Aceclofenac is nonsteroidal anti-inflammatory drug and having melting point between $149^{\circ} \mathrm{C}$ and $153^{\circ} \mathrm{C}$. Aceclofenac, a phenylacetic acid derivative, has antiinflammatory and analgesic properties; it is a potent inhibitor of cyclooxygenase that is involved in the production of prostaglandins the half-life of aceclofenac is around $4 \mathrm{~h}$.

The aim of the present study was to develop a novel multifunctional directly compressible co-processed excipients using Box-Behnken design. The dibasic calcium phosphate anhydrous (diluent), polyethylene glycol 4000 (PEG 4000) (meltable binder) and crospovidone (disintegrant) were selected for co-processing. Further, the developed co-processed excipient was utilized for the formulation of aceclofenac tablets. and reduction in development timelines and process validation

\section{MATERIALS AND METHODS}

\section{Materials}

Aceclofenac and crospovidone were received as gift from Ranbaxy Laboratories Ltd., Gurgaon, India; dibasic calcium phosphate anhydrous was obtained from Thomas Baker Chemicals Pvt. Ltd., Mumbai, India; PEG 4000 was obtained from $\mathrm{CDH}$ Pvt. Ltd., New Delhi, India; magnesium stearate and talc was obtained from Loba Chemie Pvt. Ltd., Mumbai, India. All the other ingredients were of analytical grade and used as received.

\section{Methods}

\section{Preparation of co-processed excipient}

In the present study, co-processed excipient was made using melt granulation technique. ${ }^{[14]}$ Dibasic calcium phosphate anhydrous, PEG 4000 flakes and crospovidone were passed through \#30. All the three ingredients were then weighed accurately and mixed well. This powder mix was transferred to a previously heated porcelain dish and maintained at the temperature of $60^{\circ} \mathrm{C}$. This powder blend was heated for a specified time period (4-12 min) at $60^{\circ} \mathrm{C}$ in order to break the mass into granules. After specified period of heating, porcelain dish was removed, and the granules were cooled to the room temperature with continuous stirring. The granules were passed through \#30 and kept in a tightly closed container until further use.

\section{Experimental design}

The percentage of crospovidone $(5-10 \% \mathrm{w} / \mathrm{w})$, percentage of PEG 4000 (5-15\% w/w) and the heating time (4-12 min) were selected as independent variables using Box-Behnken design. The selection of co-processed excipients and the value of ranges are given in Table 1.

The composition of the various thirteen batches as per BoxBehnken design is illustrated in Table 2.

\section{Evaluation of co-processed excipients Bulk density and tapped density}

The granules $(50 \mathrm{~g})$ were filled into a clean $100 \mathrm{ml}$ measuring cylinder and the volume (bulk volume), occupied by granules without tapping was noted $\left(\mathrm{V}_{0}\right)$. The cylinder was tapped for 500 times from a height of 2 inches and tapped volume, $\left(\mathrm{V}_{500}\right)$ was recorded. The bulk and tapped density were calculated as the ratio of mass to volume $\left(\mathrm{V}_{0}\right.$ and $\left.\mathrm{V}_{500}\right)$ respectively. ${ }^{[14]}$

\begin{tabular}{|c|c|c|c|}
\hline \multirow[t]{2}{*}{ Independent variables } & \multicolumn{3}{|c|}{ Level } \\
\hline & $\begin{array}{l}\text { Low } \\
(-1)\end{array}$ & $\begin{array}{l}\text { Intermediate } \\
\text { (0) }\end{array}$ & $\begin{array}{r}\text { High } \\
(+1)\end{array}$ \\
\hline $\mathrm{X}_{1}$ Percentage $(\mathrm{w} / \mathrm{w})$ of crospovidone & 5 & 7.5 & 10 \\
\hline$X_{2}$ Percentage $(w / w)$ of PEG 4000 & 5 & 10 & 15 \\
\hline${ }^{3}$ Heating time (min) & 4 & 8 & 12 \\
\hline
\end{tabular}

International Journal of Pharmaceutical Investigation | October 2015 | Vol 5 | Issue 4 


\begin{tabular}{|c|c|c|c|c|c|c|c|c|}
\hline $\begin{array}{l}\text { Batch } \\
\text { number }\end{array}$ & $\begin{array}{c}\mathrm{X}_{1} \text { (crospovidone, } \\
\% \mathrm{w} / \mathrm{w})\end{array}$ & $\begin{array}{c}X_{2} \text { (PEG 4000, } \\
\% \text { w/w) }\end{array}$ & $\begin{array}{c}\mathrm{X}_{3} \\
\text { (time, } \mathrm{min})\end{array}$ & $\begin{array}{l}\text { Carr's } \\
\text { index }\end{array}$ & $\begin{array}{l}\text { Hausner's } \\
\text { ratio }\end{array}$ & Friability \pm SD & $\begin{array}{l}\text { Hardness } \\
(\mathrm{kg}) \pm \mathrm{SD}\end{array}$ & $\begin{array}{c}\text { Disintegration } \\
\text { time (s) } \pm S D\end{array}$ \\
\hline $\begin{array}{l}\text { BB1 } \\
\text { BB2 } \\
\text { BB3 } \\
\text { BB4 } \\
\text { BB5 } \\
\text { BB6 } \\
\text { BB7 } \\
\text { BB8 } \\
\text { BB9 } \\
\text { BB10 } \\
\text { BB11 } \\
\text { BB12 } \\
\text { BB13 }\end{array}$ & $\begin{array}{c}\square 1(5) \\
+1(10) \\
\square 1(5) \\
+1(10) \\
\square 1(5) \\
+1(10) \\
\square 1(5) \\
+1(10) \\
0(7.5) \\
0(7.5) \\
0(7.5) \\
0(7.5) \\
0(7.5)\end{array}$ & $\begin{array}{c}\square 1(5) \\
\square 1(5) \\
+1(15) \\
+1(15) \\
0(10) \\
0(10) \\
0(10) \\
0(10) \\
\square 1(5) \\
\square 1(5) \\
+1(15) \\
+1(15) \\
0(10)\end{array}$ & $\begin{array}{c}0(8) \\
0(8) \\
0(8) \\
0(8) \\
\square 1(4) \\
\square 1(4) \\
+1(12) \\
+1(12) \\
\square 1(4) \\
+1(12) \\
\square 1(4) \\
+1(12) \\
0(8)\end{array}$ & $\begin{array}{l}26.47 \\
21.91 \\
18.47 \\
19.77 \\
25.92 \\
25.59 \\
21.20 \\
17.07 \\
20.84 \\
22.50 \\
21.51 \\
16.00 \\
25.64\end{array}$ & $\begin{array}{l}1.36 \\
1.28 \\
1.23 \\
1.25 \\
1.35 \\
1.34 \\
1.27 \\
1.21 \\
1.26 \\
1.29 \\
1.27 \\
1.19 \\
1.34\end{array}$ & $\begin{array}{c}\text { Fails } \\
\text { Fails } \\
0.374 \pm 0.02 \\
0.224 \pm 0.01 \\
0.623 \pm 0.03 \\
0.725 \pm 0.03 \\
0.480 \pm 0.02 \\
0.768 \pm 0.03 \\
\text { Fails } \\
\text { Fails } \\
0.297 \pm 0.03 \\
0.246 \pm 0.02 \\
0.548 \pm 0.03\end{array}$ & $\begin{array}{l}1.50 \pm 0.01 \\
1.75 \pm 0.02 \\
6.90 \pm 0.32 \\
4.00 \pm 0.26 \\
3.12 \pm 0.13 \\
3.00 \pm 0.19 \\
3.70 \pm 0.24 \\
2.66 \pm 0.22 \\
1.40 \pm 0.17 \\
0.80 \pm 0.28 \\
6.30 \pm 0.49 \\
4.50 \pm 0.21 \\
3.50 \pm 0.17\end{array}$ & $\begin{array}{c}53.00 \pm 0.010 \\
41.66 \pm 0.249 \\
436.20 \pm 0.568 \\
201.66 \pm 0.321 \\
114.25 \pm 0.090 \\
57.75 \pm 0.030 \\
296.0 \pm 0.376 \\
93.00 \pm 0.070 \\
37.66 \pm 0.030 \\
51.25 \pm 0.040 \\
417.00 \pm 0.745 \\
367.75 \pm 0.289 \\
122.00 \pm 0.099\end{array}$ \\
\hline
\end{tabular}

$\mathrm{X}_{1}$ : Percentage $(\mathrm{w} / \mathrm{w})$ of crospovidone, $\mathrm{X}_{2}$ : Percentage $(\mathrm{w} / \mathrm{w})$ of PEG $400, \mathrm{X}_{3}$ : Heating time $(\mathrm{min})$; the value in the bracket indicates the real values, $\mathrm{BB}$ : Box-Behnken, SD: Standard deviation, PEG: Polyethylene glycol

\section{Carr's index and Hausner's ratio}

Hausner's ratio was determined as the ratio of tapped density to bulk density. The Carr's index was obtained from the relationship. ${ }^{[15]}$

Carr's index $=([$ tappeddensity — bulkdensity $] /$ tappeddensity $)$ $\times 100$

\section{Preparation of placebo tablets using the co-processed excipient}

The granules (97\%) of batches BB1-BB13 were blended with $2 \%$ talc and $1 \%$ magnesium stearate for $2 \mathrm{~min}$. Tablets were compressed using $10 \mathrm{~mm}$ diameter flat faced punches and die on a single punch tablet machine (Pharmaceutical Machinery Mfg. Works, Indore, India). The average weight of the tablet was $450 \mathrm{mg}$.

\section{Evaluation of placebo tablets (from co-processed excipients) \\ Hardness}

The hardness of the tablets was determined using a Monsanto hardness tester (Pharmalab, Ahmedabad, India). The results were the average of 10 determinations. ${ }^{[16]}$

\section{Friability}

The friability of the tablets was determined using a Roche Friabilator (Labindia Instruments Pvt. Ltd., India). The 20 tablets (known weight) were placed in the drum and rotated for 100 times. After 100 revolutions, the tablets were removed from the drum, dedusted, and the loss in weight caused by fracture or abrasion was recorded as a percentage friability. ${ }^{[17]}$

\section{Disintegration time}

The time required for the disintegration of six tablets was measured using disintegration test apparatus (Excel Enterprise, Kolkata, India). A volume of $900 \mathrm{ml}$ of distilled water at $37^{\circ} \mathrm{C} \pm$ $2{ }^{\circ} \mathrm{C}$ was used as the disintegration medium. ${ }^{[18]}$

\section{Characterization of co-processed excipient}

Selected batches of co-processed granules (BB3 and BB12) were further characterized for the following parameters.

\section{Particle size distribution}

Particle size distribution was performed on selected batches (BB3 and BB12) using a mechanical sieve shaker (Pritec Gurprit Electrical Co., India). A nest of standard sieves (30, 44, 60, 85 and 170 mesh) was used. The 30, 44, 60, 85 and 170 mesh has 500, 355, 250, 180 and $90 \mu \mathrm{m}$ opening, respectively. The sieves were agitated on a sieve shaker for $5 \mathrm{~min}$, and the weight of granules retained on each sieve was noted. ${ }^{[19]}$

\section{Granular friability index}

The co-processed granules of batches BB3 and BB12 were rotated for $60 \mathrm{~min}$ at $25 \mathrm{rpm}$ in roche friabilator. The friabilator treated granules were evaluated for the mean particle size using sieving technique. The granular friability index was calculated as the ratio of the mean particle size of the friabilator-treated granules to the mean particle size of the untreated granules. ${ }^{[20]}$

\section{Moisture uptake study}

The co-processed granules were spreaded in a petri dish, and the dish was placed in stability chamber (Khera Instruments Pvt. Ltd., India) maintained at $75 \% \mathrm{RH}$ and $40^{\circ} \mathrm{C}$. The percentage increase in weight was noted after 24 h. ${ }^{[21]}$

\section{Differential scanning calorimetry}

Differential scanning calorimetry (DSC) measurements were carried out with a type of DSC Q10 V9.9 Build 303 instrument (Waters, India). The instrument was calibrated using indium as standard. Samples ( $2 \mathrm{mg}$ ) were placed in sealed aluminum pans and heated from $25^{\circ} \mathrm{C}$ to $300^{\circ} \mathrm{C}$ at a rate of $10^{\circ} \mathrm{C} / \mathrm{min}$ under nitrogen atmosphere $(100 \mathrm{ml} / \mathrm{min})$, with empty pan as reference.

\section{Fourier transform infrared spectroscopy}

A Fourier transform infrared spectroscopy (FT-IR) measurement was conducted using an FT-IR instrument (FT-IR, 640 plus, Jasco) using thin pellets containing $1 \mathrm{mg}$ of each sample dispersed in $100 \mathrm{mg}$ of $\mathrm{KBr}$. The spectrum was recorded in the $400-2,000 / \mathrm{cm}$ range with a spectral resolution of $2 / \mathrm{cm}$. 


\section{Scanning electron microscopy}

The shape and surface morphology of the developed co-processed granule was examined by Scanning electron microscope (SEM JSM-6510, Jeol). The sample was analyzed after coating with gold-palladium alloy.

\section{Formulation and evaluation of aceclofenac tablets}

In order to demonstrate the compressibility and the tableting performance of the developed co-processed excipient, tablets of a model drug (aceclofenac) were formulated. Four batches of aceclofenac tablets were prepared and evaluated. Two batches (CP1 and CP2) were prepared by direct compression method using co-processed granules of Batch BB3 and BB12, respectively and two batches (WG1 and WG2) were prepared by wet granulation method [Table 3]. Batch CP 1 contains co-processed granules having 5\% of crospovidone, 15\% PEG 4000 and $80 \%$ of dibasic calcium phosphate and the batch WG 1 composed the same percentage of these excipients. Similarly, batch CP 2 contains co-processed granules having $7.5 \%$ of crospovidone, $15 \%$ of PEG 4000 and $77.5 \%$ of dibasic calcium phosphate and the batch WG 2 composed the same percentage of these excipients. The composition of the adjuvants in batch WG1 and WG2 was in correspondence with batch CP1 and CP2, respectively. The tablets were prepared using 10-mm diameter flat faced punches and die on a single punch tablet machine. The average weight of the tablet was $450 \mathrm{mg}$. Further, the tablets were evaluated for hardness, disintegrating time and in vitro release studies.

\section{In vitro drug release}

In vitro dissolution study of aceclofenac tablet was carried out in phosphate buffer $\left(\mathrm{pH} 7.5,900 \mathrm{~mL}, 37^{\circ} \mathrm{C} \pm 0.5^{\circ} \mathrm{C}\right)$ using USP apparatus Type II apparatus (50 rpm) (Labindia DS 8000, India). Samples $(10 \mathrm{~mL})$ were withdrawn at predetermined time intervals, filtered through Whatman filter paper, and analyzed at $273 \mathrm{~nm}$ using ultraviolet-visible spectroscopy spectrophotometer (Shimadzu, Japan). The same volume $(10 \mathrm{ml})$ of fresh dissolution medium $\left(37^{\circ} \mathrm{C} \pm 0.5^{\circ} \mathrm{C}\right)$ was replenished immediately after the withdrawal of the sample. ${ }^{[22]}$

\begin{tabular}{|c|c|c|c|c|}
\hline \multirow[t]{2}{*}{ Ingredients } & \multicolumn{4}{|c|}{ Quantity (mg) } \\
\hline & $\begin{array}{l}\text { Batch } \\
\text { CP 1* }\end{array}$ & $\begin{array}{l}\text { Batch } \\
\text { CP } 2\end{array}$ & $\begin{array}{l}\text { Batch } \\
\text { WG } 1\end{array}$ & $\begin{array}{l}\text { Batch } \\
\text { WG } 2\end{array}$ \\
\hline $\begin{array}{l}\text { Aceclofenac } \\
\text { CP }\end{array}$ & $\begin{array}{c}100 \\
329.75 \\
\text { (batch BB3) }\end{array}$ & $\begin{array}{c}100 \\
329.75 \\
\text { (batch BB12) }\end{array}$ & $\begin{array}{c}100 \\
-\end{array}$ & $\begin{array}{c}100 \\
-\end{array}$ \\
\hline $\begin{array}{l}\text { Dibasic calcium } \\
\text { phosphate anhydrous }\end{array}$ & - & - & 263.80 & 255.56 \\
\hline $\begin{array}{l}\text { PEG } 4000 \\
\text { Crospovidone }\end{array}$ & $\begin{array}{l}- \\
-\end{array}$ & $\begin{array}{l}- \\
-\end{array}$ & $\begin{array}{l}49.46 \\
16.49\end{array}$ & $\begin{array}{l}49.46 \\
24.73\end{array}$ \\
\hline Talc & 9.00 & 9.00 & 9.00 & 9.00 \\
\hline Magnesium stearate & 4.50 & 4.50 & 4.50 & 4.50 \\
\hline Aspartame & 4.50 & 4.50 & 4.50 & 4.50 \\
\hline Lemon flavor & 2.25 & 2.25 & 2.25 & 2.25 \\
\hline
\end{tabular}

\section{RESULTS AND DISSCUSSION}

Melt granulation technique is a cost effective method of production as it can be adopted using conventional equipment, involves short processing time and do not require water or any other solvent and does not have any environmental concerns. ${ }^{[23]}$ Dibasic calcium phosphate is the most widely used pharmaceutical excipient. However, dibasic calcium phosphate has an extremely low compressibility, thus, making it unsuitable for direct compression purpose. ${ }^{[24]}$ Further, powdered dibasic calcium phosphate offers the problem of poor flowability. PEG 4000 was selected as meltable binder. PEG 4000 melts in the temperature range of $50-58^{\circ} \mathrm{C}$, therefore, avoids the problem of melting or softening during handling, storage, processing and instability of heat labile materials. Dibasic calcium phosphate anhydrous is practically insoluble in water, therefore, necessitates the use of disintegrant. The disintegrant employed here is crospovidone. Crospovidone being a plastic material in combination with brittle material (dibasic calcium phosphate) helps to improve compaction performance, flow properties, strain rate sensitivity and so on. ${ }^{[25]}$ This particular trio of excipients served two purposes. Firstly, it ensured multifunctionality in the developed co-processed excipient, thereby, reducing the number of excipients in the inventory. Secondly, this being, a combination of brittle (dibasic calcium phosphate) and plastic material (crospovidone) ensured better compressibility of developed co-processed excipient. ${ }^{[25]}$ The most important attributes for good flow and good compression are Carr's index, hardness and disintegrating time. Carr's index is a measure to know the property of the blend to be compressed and relative importance of interparticulate interaction. The smaller the Carr's index the better the flow properties. ${ }^{[2]}$ The hardness test was performed to provide a measure of tablet strength the resistance of tablet from shipping or breakage, under conditions of storage, transportation and handling before usage depends on its hardness. ${ }^{[26]}$ The disintegrating test is performed to find out the time; it takes for a solid oral dosage to complete disintegrate. However, if the disintegrating time is too high; it means that the tablet is too highly compressed. ${ }^{[26]}$

\section{Evaluation and characterization of co-processed excipients}

To study the effect of various factors, the co-processed excipients were evaluated in terms of Carr's index, hardness and disintegration time. The selected batches were further studied for friability, particle size distribution, friability index, moisture uptake studies, DSC, FT-IR, SEM studies.

\section{Characterization of co-processed granules Carr's index}

Carr's index $<15$ indicates good flowability whereas Carr's index between 16 and 20 and 21 and 25 indicates fair and passable flow respectively. ${ }^{[15]}$ Table 3 reveals that batches (BB3, BB4, BB8 and $\mathrm{BB} 12$ ) exhibited fair flow, batch BB1 indicate poor flow and rest other batches indicated passable flow. The fair flow of the batches (BB3, BB4, BB8 and BB12) may be due to a higher percentage of binder $(15 \%)$ and optimum heating time that is, 8 or $12 \mathrm{~min}$. 
The fair flow of these batches can be attributed to high value of percentage of PEG $4000\left(\mathrm{X}_{2}\right)$ and heating time $\left(\mathrm{X}_{3}\right)$, and low value of crospovidone $\left(\mathrm{X}_{1}\right)$. The effect was the highest in case of heating time and lowest in case of percentage of crospovidone [Figure 1].

ANOVA was applied on the Carr's index to study the fitting and significance of the model. $F$-test was carried out to compare the regression mean square with residual mean square. The ratio $F=3.14$ shows regression to be significant [Table 4].

Mathematical model for Carr's index is shown in equation (2)

$$
\begin{aligned}
Y_{1}= & 25.64-0.965 \mathrm{X}_{1}-1.996 \mathrm{X}_{2}-2.136 \mathrm{X}_{3}-0.876\left(\mathrm{X}_{1}\right)^{2}- \\
& 3.109\left(\mathrm{X}_{2}\right)^{2}-2.319\left(\mathrm{X}_{3}\right)^{2}+1.465 \mathrm{X}_{1} \mathrm{X}_{2}-0.95 \mathrm{X}_{1} \mathrm{X}_{3}- \\
& 1.792 \mathrm{X}_{2} \mathrm{X}_{3}
\end{aligned}
$$

Where $\mathrm{Y}_{1}=$ Carr's index, $\mathrm{X}_{1}=$ crospovidone (\%), $\mathrm{X}_{2}=\mathrm{PEG} 4000$ $(\%), X_{3}=$ time $(\min ), X_{1} X_{2}, X_{2} X_{3}$ and $X_{1} X_{3}$ shows interaction terms and $X_{1}^{2}, X_{2}^{2}$ and $X_{3}^{2}$ shows square terms.

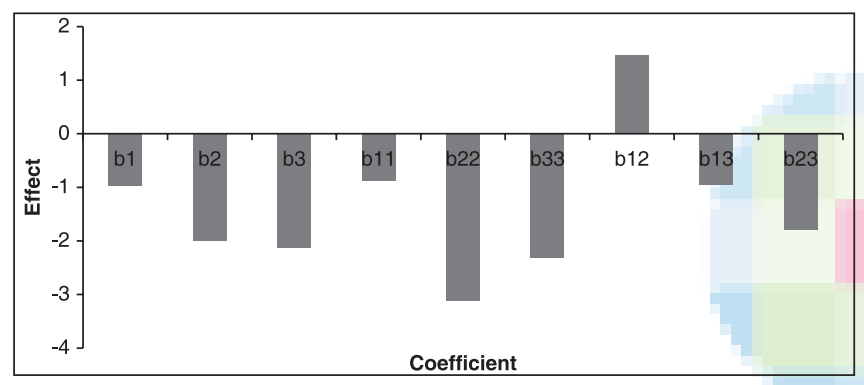

Figure 1: Effect plot for Carr's index. (b1, b2, b3 = coefficients of main effects; b11, b22, b33 = coefficients of square terms; b12, b13, b23 $=$ coefficients of interaction terms)

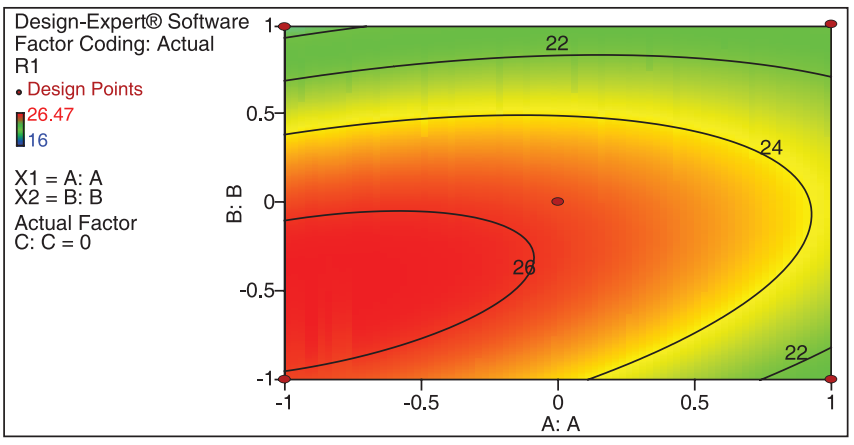

Figure 3: Contour plot of Carr's index as a function of formulation variables
The three-dimensional response surface plots and the corresponding contour plots for Carr's index are shown in Figures 2 and 3, respectively the estimated model, therefore, may be used as a response surface for Carr's index.

\section{Characterization of placebo tablets from co-processed granules \\ Hardness}

Hardness $\geq 4 \mathrm{~kg}$ was selected as the criteria for the selection of an appropriate batch of placebo tablets. Batches BB3, BB4, BB11 and BB12 meet the above criteria, while, the rest other batches failed to meet the criteria. The good performance of these batches in the hardness test may be attributed to the higher concentration of binder (15\%). From the results of multiple regression analysis, it can be concluded that hardness decreases at the high level of crospovidone, PEG 4000 and heating time. The effect was highest in case of percentage of PEG 4000 and lowest in case of heating time [Figure 4].

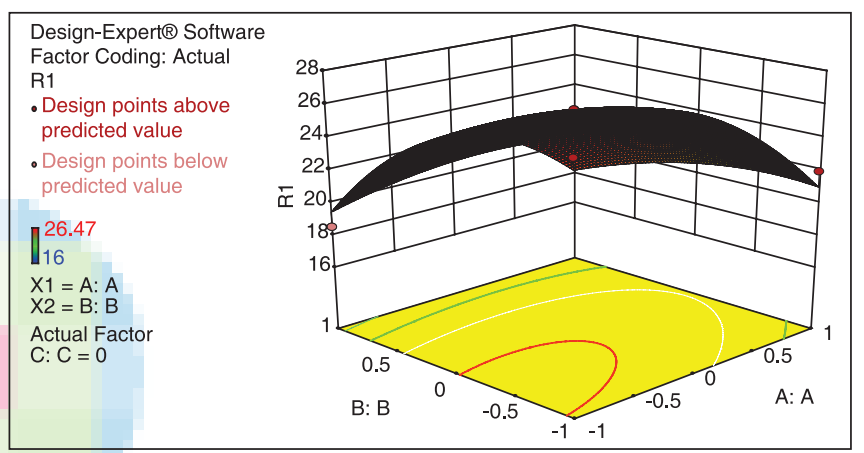

Figure 2: Three-dimensional response surface of Carr's index as a function of formulation variables

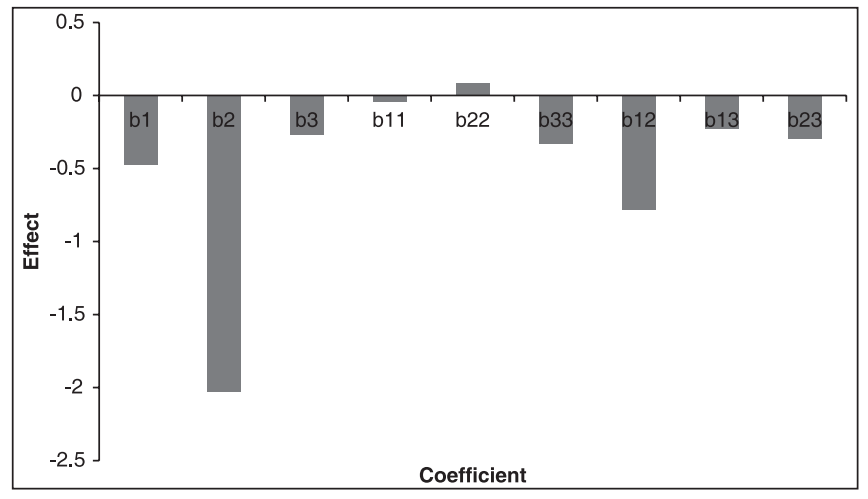

Figure 4: Effect plot for Hardness (b1, b2, b3 = coefficients of main effects; b11, b22, b33 = coefficients of square terms; b12, b13,

\begin{tabular}{|c|c|c|c|c|c|c|c|c|c|c|c|c|c|}
\hline \multirow[t]{2}{*}{ Data } & \multirow{2}{*}{$\begin{array}{l}\text { Degree of } \\
\text { freedom }\end{array}$} & \multicolumn{3}{|c|}{ Sum of squares } & \multicolumn{3}{|c|}{ Mean squares } & \multicolumn{3}{|c|}{$\mathbf{F}$} & \multicolumn{3}{|c|}{ Significance $F$} \\
\hline & & A & B & C & A & B & C & A & B & C & A & B & C \\
\hline Regression & 9 & 127.44 & 38.86 & 262,174 & 14.16 & 4.32 & 29,130 & 3.14 & 10.31 & 8.01 & $0.187981^{*}$ & $0.040259 *$ & $0.056992 *$ \\
\hline Residual & 3 & 13.52 & 1.26 & 10,915 & 4.51 & 0.42 & 3638 & - & - & - & - & - & - \\
\hline Total & 12 & 140.96 & 40.12 & 273,089 & - & - & - & - & - & - & - & - & - \\
\hline
\end{tabular}
b23 $=$ coefficients of interaction terms)

Table 4: ANOVA on the regression of Carr's index, hardness and disintegration time

$* P<0.05 \%$, A: Carr's index, B: Hardness, C: Disintegration time, ANOVA: Analysis of variance 
ANOVA was applied on the hardness to study the fitting and significance of the model. $F$-test was carried out to compare the regression mean square with residual mean square. The ratio $F=10.31$ shows regression to be significant [Table 4].

Mathematical model for hardness is shown in equation (3)

$$
\begin{aligned}
Y_{2}= & 3.5-0.477 \mathrm{X}_{1}-2.031 \mathrm{X}_{2}-0.271 \mathrm{X}_{3}-0.046\left(\mathrm{X}_{1}\right)^{2}+ \\
& 0.083\left(\mathrm{X}_{2}\right)^{2}-0.333\left(\mathrm{X}_{3}\right)^{2}-0.787 \mathrm{X}_{1} \mathrm{X}_{2}-0.229 \mathrm{X}_{1} \mathrm{X}_{3}- \\
& 0.3 \mathrm{X}_{2} \mathrm{X}_{3}
\end{aligned}
$$

$\mathrm{Y}_{2}=$ hardness, $\mathrm{X}_{1}=$ crospovidone $(\%), \mathrm{X}_{2}=$ PEG $4000(\%)$, $\mathrm{X}_{3}=$ time $(\mathrm{min}), \mathrm{X}_{1} \mathrm{X}_{2}, \mathrm{X}_{2} \mathrm{X}_{3}$ and $\mathrm{X}_{1} \mathrm{X}_{3}$ shows interaction terms and $\mathrm{X}_{1}{ }^{2}, \mathrm{X}_{2}{ }^{2}$ and $\mathrm{X}_{3}{ }^{2}$ shows square terms. The three-dimensional response surface plots and the corresponding contour plots for hardness are shown in Figures 5 and 6, respectively the estimated model, therefore, may be used as a response surface for hardness.

\section{Disintegration time}

Disintegration time of uncoated tablet should be $<15$ min. ${ }^{[18]}$ Disintegration time of all the batches was well below the selection criteria. From the results of multiple regression analysis, it can be concluded that disintegration time decreases at the high level of crospovidone and increases at the high level of PEG 4000 and

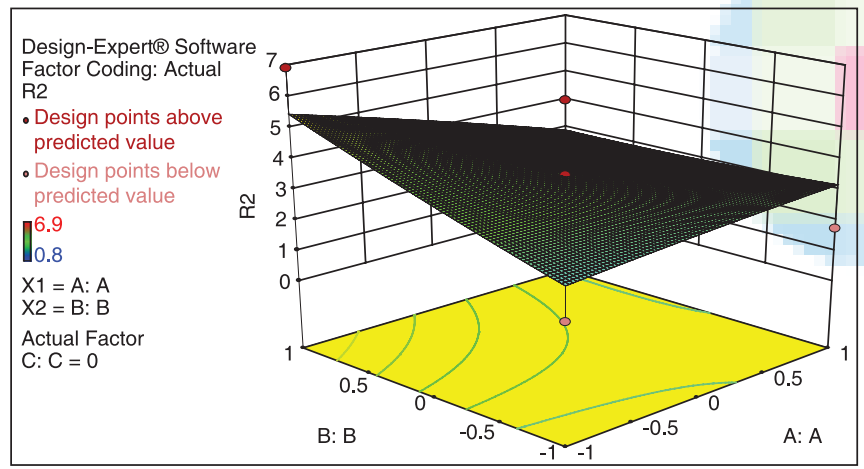

Figure 5: Three-dimensional response surface of hardness as a function of formulation variables

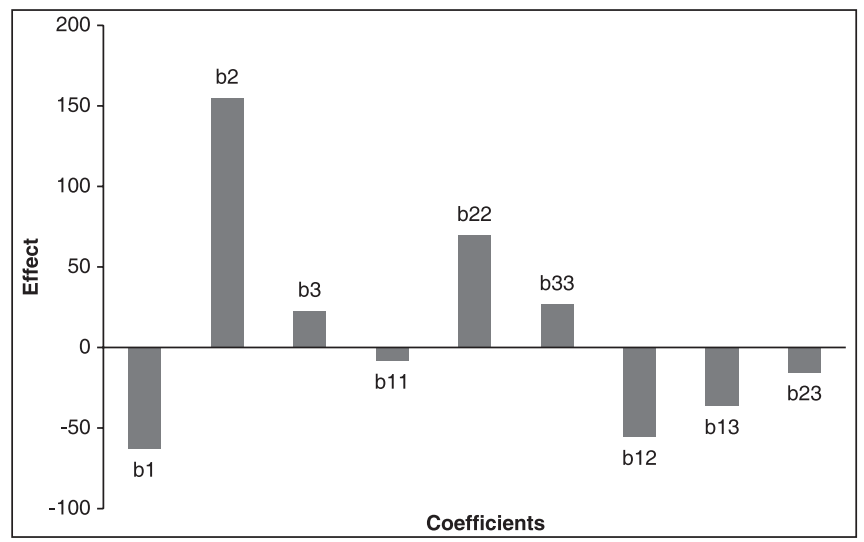

Figure 7: Effect plot for disintegration time (b1, b2, b3 = coefficients of main effects; b11, b22, b33 = coefficients of square terms; b12, b13, b23 = coefficients of interaction terms) heating time. The effect was highest in case of percentage of PEG 4000 and lowest in case of heating time [Figure 7].

ANOVA was applied on the disintegration time to study the fitting and significance of the model. $F$-test was carried out to compare the regression mean square with residual mean square. The ration $F=8.01$ shows regression to be significant [Table 4].

Mathematical model for disintegration time is shown in equation (4)

$$
\begin{aligned}
Y_{3}= & 122-63.172 X_{1}+154.88 X_{2}+22.668 X_{3}-8.517\left(X_{1}\right)^{2}+ \\
& 69.647\left(\mathrm{X}_{2}\right)^{2}+26.767\left(\mathrm{X}_{3}\right)^{2}-55.8 \mathrm{X}_{1} \mathrm{X}_{2}-36.625 \mathrm{X}_{1} \mathrm{X}_{3}- \\
& 15.71 \mathrm{X}_{2} \mathrm{X}_{3}
\end{aligned}
$$

$\mathrm{Y}_{3}=$ disintegrating time, $\mathrm{X}_{1}=$ crospovidone $(\%), \mathrm{X}_{2}=\mathrm{PEG}$ $4000(\%), X_{3}=$ time $(\min ), X_{1} X_{2}, X_{2} X_{3}$ and $X_{1} X_{3}$ shows interaction terms and $\mathrm{X}_{1}^{2}, \mathrm{X}_{2}^{2}$ and $\mathrm{X}_{3}^{2}$ shows square terms. The three-dimensional response surface plots and the corresponding contour plots for disintegrating time are shown in Figures 8 and 9, respectively the estimated model, therefore, may be used as a response surface for disintegrating time.

\section{Friability}

Friability of uncoated tablets should be $<1 \%$ as per pharmacopeial standards. ${ }^{[17]}$ Batches BB1, BB2, BB7 and BB8 could not pass the friability test, while, the rest other batches meet the selection criteria. The unsatisfactory performance of the batches BB1,

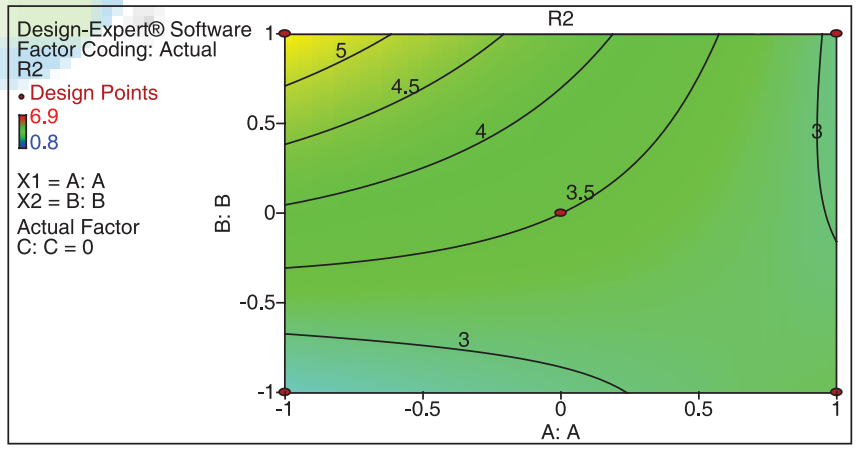

Figure 6: Contour plot of hardness as a function of formulation variables

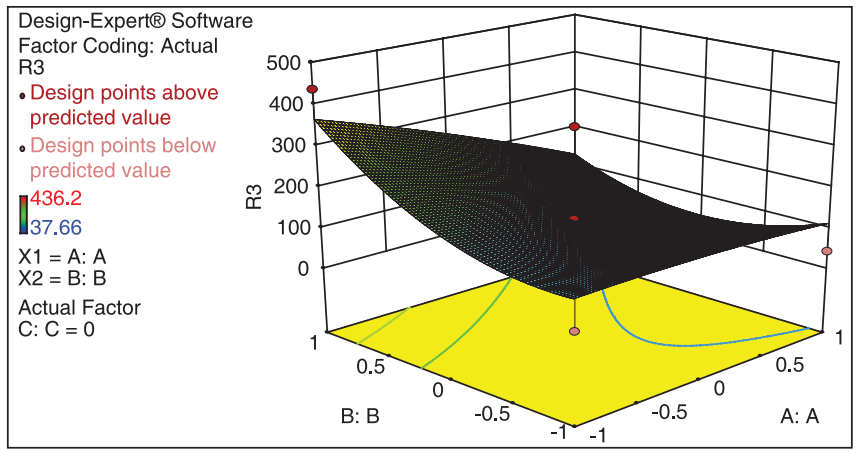

Figure 8: Three-dimensional response surface of disintegrating time as a function of formulation variables 


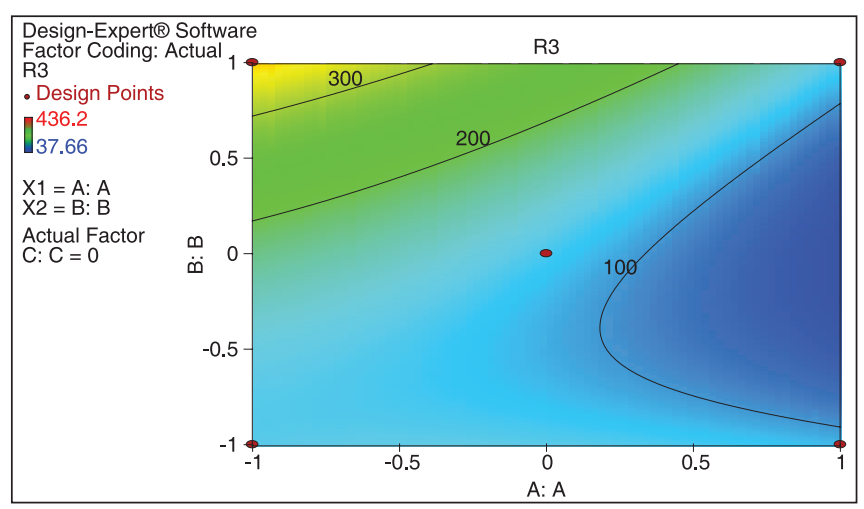

Figure 9: Contour plot of disintegrating time as a function of formulation variables

$\mathrm{BB} 2, \mathrm{BB} 7$ and $\mathrm{BB} 8$ in the friability test may be due to the low percentage of the binder $(5 \%)$.

From batches BB1-BB13, only three batches (BB3, BB4 and $\mathrm{BB} 12)$ were able to meet the selection criteria that is, hardness $\geq 4 \mathrm{~kg}$, friability $<1 \%$, disintegration time $<15 \mathrm{~min}$ and Carr's index $\leq 20$. Out of these three batches, batches BB3 and BB12 were selected for further characterization because batch BB3 had the highest value for hardness (6.90) and batch BB12 exhibited the lowest value for Carr's index (16.00).

\section{Evaluation of co-processed granules Particle size distribution}

Particle size distribution of both batches BB3 and batch BB12 are shown in Figure 10. Particle size distribution of the sample has a profound influence on the physical properties of the powder such as bulk density, compressibility and especially flowability. The co-processed granules of batch BB3 and batch BB12 exhibited mean particle size of $340 \mu \mathrm{m}$ and $290 \mu \mathrm{m}$, respectively, and it may be the reason for the better flowability of co-processed granules.

\section{Granular friability index}

This test evaluates the ability of granules to withstand abrasion and mechanical shock during processing, packaging and shipping. After $60 \mathrm{~min}$, the granular friability index for batch $\mathrm{BB} 3$ and batch BB12 was found to be 0.82 and 0.80 , respectively. The value of granular friability index close to 1 indicates that granules are mechanically strong and can easily withstand external abrasion and mechanical shock. ${ }^{[20]}$

\section{Moisture uptake study}

Moisture uptake study is important because water absorption by adjuvants can influence the chemical and physical stability of the dosage form. The granules of batch BB3 and batch BB12 absorbed $0.21 \% \mathrm{w} / \mathrm{w}$ and $1.06 \% \mathrm{w} / \mathrm{w}$ of moisture, respectively when stored at $75 \% \mathrm{RH}$ and $40^{\circ} \mathrm{C}$ for $24 \mathrm{~h}$. The results revealed that both the batches are moisture insensitive. The higher moisture content of batch BB12 in comparison to batch BB3 may be attributed to the higher concentration of hygroscopic powder that is, crospovidone.

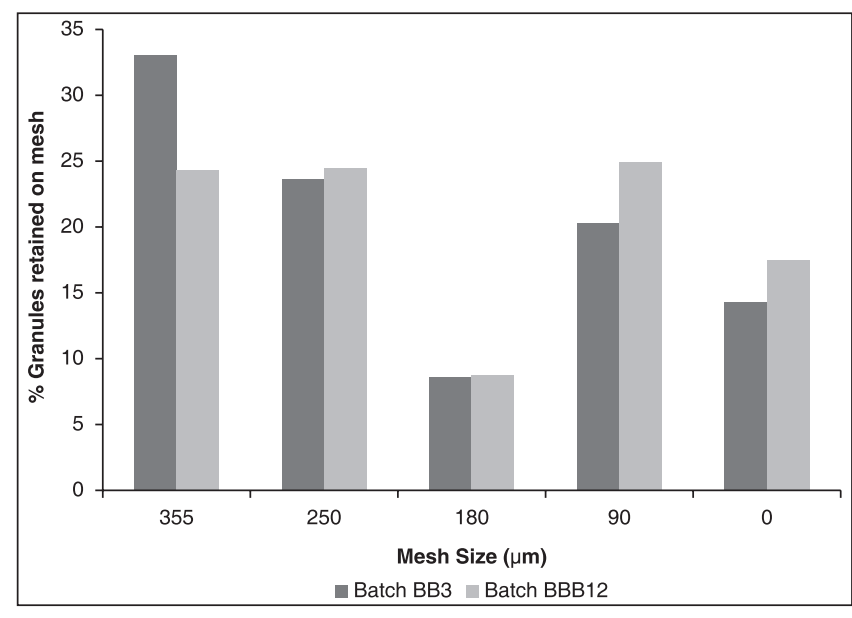

Figure 10: Particle size distribution of Batch BB3 and Batch BB12

\section{Differential scanning calorimetric studies}

The DSC thermogram of dibasic calcium phosphate anhydrous, PEG 4000, crospovidone, co-processed granules of batch $\mathrm{BB} 3$, co-processed granules of batch BB12, physical mixture corresponding to batch $\mathrm{BB} 3$ and physical mixture corresponding to batch BB12 are shown in Figure 11. The thermal behavior of dibasic calcium phosphate anhydrous showed no DSC pattern till $300^{\circ} \mathrm{C}$. The DSC scan of PEG 4000 showed a large melting peak, with a peak onset at $63.07^{\circ} \mathrm{C}$ and an exothermal inflection at about $150^{\circ} \mathrm{C}$, due to its instability on heating at high temperature. Crospovidone scan showed a broad endotherm with a maximum at $94.84^{\circ} \mathrm{C}$, due to the water absorbed by the hygroscopic crosslinked polymer. In the DSC scan of the co-processed granules and physical mixtures, only thermal event that was detected was the fusion of PEG 4000.

\section{Fourier transform infrared spectroscopy}

The FT-IR spectra of dibasic calcium phosphate anhydrous, PEG 4000, crospovidone, co-processed granules of batch $\mathrm{BB} 3$, co-processed granules of batch BB12, physical mixture corresponding to batch $\mathrm{BB} 3$ and physical mixture corresponding to batch BB12 are shown in Figure 12. The FT-IR spectra of the physical mixtures are almost a superimposition of the FT-IR profile contributed by dibasic calcium phosphate anhydrous, PEG 4000 and crospovidone. The dominance of principle bands of dibasic calcium phosphate anhydrous in the physical mixture is a result of its high percentage in the mixture. The FT-IR spectra of co-processed granules showed almost the same bands as the physical mixtures, which suggest the absence of any detectable chemical interaction in the co-processed granules.

\section{Scanning electron microscopy}

The shape and surface topography of the developed co-processed granule was examined by SEM. Sample was dusted on a doublesided adhesive tape applied previously to an aluminum stub. Excess sample was removed, and stub sputter coated with a 30 nm layer of gold-palladium. Sample was then observed with a scanning electron microscope. Co-processed granules were found to be random in size and nearly spherical in shape [Figure 13]. 


\section{Evaluation of aceclofenac tablets}

In order to demonstrate the tableting performance of the developed co-processed granules, aceclofenac tablets were prepared and evaluated. Aceclofenac tablets were also prepared by conventional wet granulation method, using the same composition of excipients as available in co-processed granules, so, as to serve the purpose of reference. The evaluation result of aceclofenac tablets for hardness, friability, and disintegration time are shown in Table 5 and results for in vitro drug release are shown in Figure 14. The aceclofenac tablets (batch CP1 and CP2) prepared using co-processed granules hold good tableting characteristics. Further, aceclofenac tablets prepared using the co-processed excipient showed better hardness, disintegration time and in vitro drug release as compared to aceclofenac tablets prepared using conventional wet granulation method.

\section{CONCLUSION}

Co-processing of dibasic calcium phosphate anhydrous with PEG 4000 and crospovidone, using melt granulation technique has resulted into a directly compressible vehicle with improved

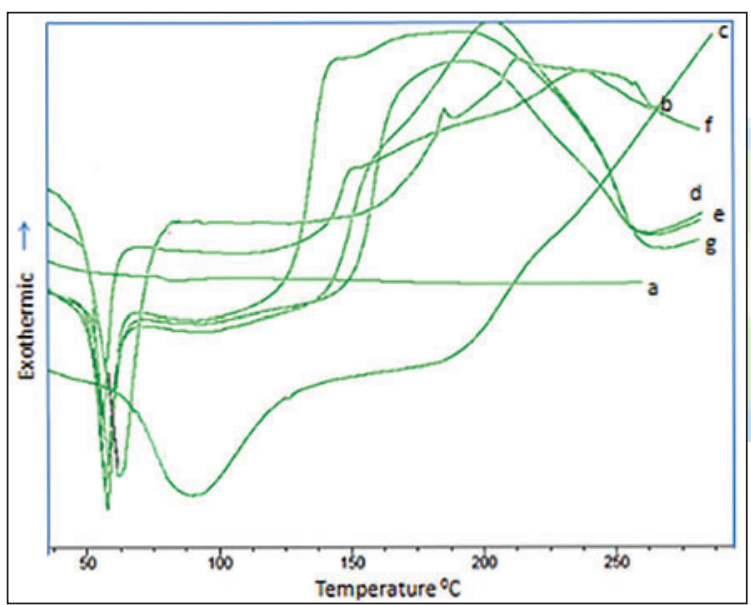

Figure 11: Differential scanning calorimetry thermogram of (a) dibasic calcium phosphate anhydrous; (b) polyethylene glycol 4000; (c) crospovidone; (d) co-processed granules (batch BB3); (e) co-processed granules (batch BB12); (f) physical mixture (corresponding to batch BB3); (g) physical mixture (corresponding to batch BB12)

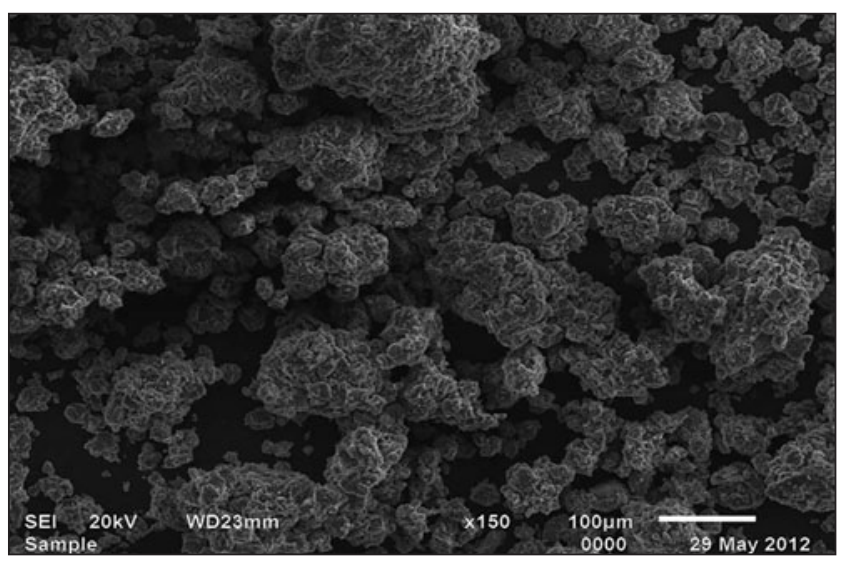

Figure 13: Scanning electron microscopy image of co-processed granules characteristics. The co-processed excipient proved to be superior in terms of flowability and compressibility. Aceclofenac tablets prepared using co-processed excipients showed better hardness, disintegration time and in vitro drug release in comparison to the aceclofenac tablets prepared using conventional wet granulation method. Therefore, it may be concluded that the co-processed excipient developed in the present study can be introduced as a novel co-processed excipient for improvement of tableting characteristics and further scale up studied for co-processed excipients have been advocated.

\begin{tabular}{lccc}
$\begin{array}{l}\text { Table 5: Results of evaluation of aceclofenac } \\
\text { tablets }\end{array}$ & & & \\
\hline Batch & $\begin{array}{c}\text { Hardness } \\
(\mathbf{k g}) \pm \text { SD }\end{array}$ & Friability \pm SD & $\begin{array}{c}\text { Disintegration time } \\
\text { (min.s) } \pm \text { SD }\end{array}$ \\
\hline CP1 & $3.7 \pm 0.03$ & $0.44 \pm 0.04$ & $8.30 \pm 0.07$ \\
CP2 & $3.1 \pm 0.04$ & $0.33 \pm 0.02$ & $7.15 \pm 0.17$ \\
WG1 & $2.4 \pm 0.03$ & $0.22 \pm 0.01$ & $16.00 \pm 0.26$ \\
WG2 & $2.6 \pm 0.01$ & $0.21 \pm 0.01$ & $19.45 \pm 0.30$ \\
\hline
\end{tabular}

CP: Co-processed granules, WG: Wet granulation, SD: Standard deviation

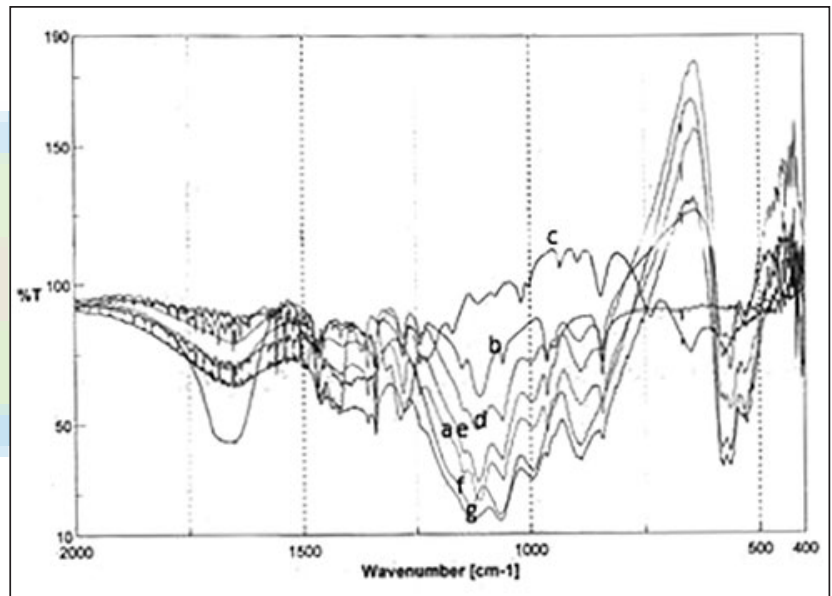

Figure 12: Fourier transform infrared spectroscopy spectra of (a) dibasic calcium phosphate anhydrous; (b) polyethylene glycol 4000; (c) crospovidone; (d) co-processed granules (batch BB3); (e) co-processed granules (batch BB12), (f) physical mixture (corresponding to Batch BB3); (g) physical mixture (corresponding to batch BB12)

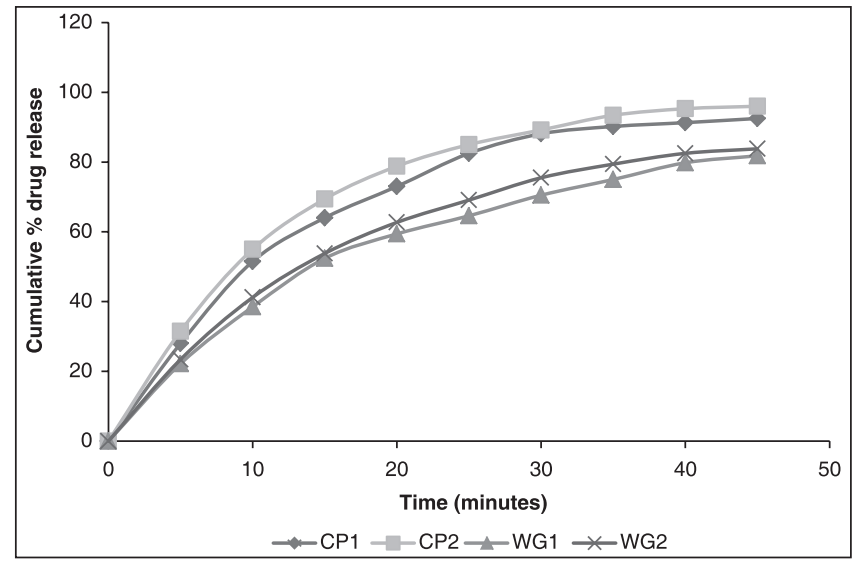

Figure 14: Dissolution profile of different batches of aceclofenac tablets 


\section{REFERNCES}

1. Banker GS, Anderson NR. Tablets. In: Lachman L, Lieberman HA, Kanig J L, editors. The Theory and Practice of Industrial Pharmacy. $3^{\text {rd }}$ ed. Philadelphia, PA: Lea and Febiger; 1986. p. 293-345.

2. Shangraw RF, Demarest DA. A survey of current industrial practices in the formulation and manufacture of tablets and capsules. Pharm Technol 1993;17:32-44.

3. Bone A, Izebound E. Excipients on the move. IPEC Europe news. 2004. Available from: http://www.ipec-europe.org/ UPLOADS/2004_October.pdf. [Last accessed on 2011 Mar 15].

4. Moreton RC. Tablet excipients to the year 2001: A look into the crystal ball. Drug Dev Ind Pharm 1996;22:11-23.

5. Patel RP, Bhavsar M. Directly compressible materials via co-processing. Int J Pharm Tech Res 2009;1:745-53.

6. Russell R. Synthetic excipients challenge all-natural organics - Offer advantages/challenges to developers and formulators. Pharm Technol 2004;27:38-50.

7. Reimerdes D. the near future of tablet excipients. Manuf $\mathrm{Chem}$ 1993;64:14-5.

8. Reimerdes D, Aufmuth KP. Tabletting with co-processed lactosecellulose excipients. Manuf Chem 1992;63:21-4.

9. York P. Crystal engineering and particle design for the powder compaction process. Drug Dev Ind Pharm 1992;18:677-721.

10. Belda PM, Mielck JB. the tabletting behaviour of cellactose compared with mixtures of celluloses with lactose. Eur J Pharm Biopharm 1996;42:325-30.

11. Nachegari SK, Bansal AK. Coprocessed excipients for solid dosage forms. Pharm Technol 2004;28:52-64.

12. Garg N, Dureja H, Kaushik D. Co-processed excipients: A patent review. Recent Pat Drug Deliv Formul 2013;7:73-83.

13. Schoneker D. Co-processed excipients: IPEC guidelines. 2011. Available from: http://www.ipecamericas.org/content/excipientfest2011-presentations. [Last accessed on 2011 Nov 24].

14. Gohel MC, J ogani PD, Bariya SE. Development of agglomerated directly compressible diluent consisting of brittle and ductile materials. Pharm Dev Technol 2003;8:143-51.

15. Carr RL. Evaluating flow properties of solids. Chem Eng $1965 ; 72: 163-8$
16. Kusum AP, Fudholi A, Nugroho AK. Optimization direct compression's co-processed excipients microcrystalline cellulose pH 102 and povidone ${ }^{\circledR}$ K30. IOSR J Pharm Biol Sci 2014;9:65-9.

17. Gangurde A, Patole RK, Sav AK. A novel directly compressible co-processed excipient for sustained release formulation. J Appl Pharm Sci 2013;3:88-97.

18. USP 24-NF 19. Disintegration. Rockville: United States Pharmacopeial Convention Inc.; 2000. p. 1174, 941, 2148.

19. Gohel MC, Jogani PD. A review of co-processed directly compressible excipients. J Pharm Pharm Sci 2005;8:76-93.

20. Gohe MC, J ogani PD. Exploration of melt granulation technique for the development of coprocessed directly compressible adjuvant containing lactose and microcrystalline cellulose. Pharm Dev Technol 2003;8:175-85.

21. Pusapati RT, Kumar MK, Rapeti SS, Murthy T. Development of co-processed excipients in the design and evaluation of atorvastatin calcium tablets by direct compression method. Int J Pharm Investig 2014;4:102-6.

22. Indian Pharmacopoeia. Monographs on Drug Substances, Dosage forms and Pharmaceutical Aids, Acelofenac Tablets. Vol. 2. Ghaziabad, India: The Indian Pharmacopoeia Commission; 2007. p. 682.

23. Patel SS, Patel NM, Soniwala MM. Statistical development of a multifunctional directly compressible co-processed excipient using the melt agglomeration technique. Am J Plant Sci 2009;4:340-56.

24. Deorkar N, Farina J, Miinea L, Randive S. Directly compressible high functionality granular dibasic calcium phosphate based co-processed excipient. United States Patent; 2011/0229527.

25. Saha S, Shahiwala AF. Multifunctional coprocessed excipients for improved tabletting performance. Expert Opin Drug Deliv 2009;6:197-208.

26. Manikandan M, Kannan K, Manavalan M. Design and evaluation of amoldipine besilate and atorvastatin calcium tablets. Res J Pharm Bio Chem Sci 2012;3:425-34.

How to cite this article: Garg N, Pandey P, Kaushik D, Dureja $H$. Development of novel multifunction directly compressible coprocessed excipient by melt granulation technique. Int J Pharma Investig 2015;5:266-74.

Source of Support: Nil. Conflict of Interest: None declared. 